\title{
EXPLOITING TEXTURED 3D MODELS FOR DEVELOPING SERIOUS GAMES
}

\author{
G. Kontogianni, A. Georgopoulos \\ Laboratory of Photogrammetry, School of Rural and Surveying Engineering, National Technical University of Athens - \\ 15780 Zografou Athens, Greece \\ georgia.kontog@gmail.com,drag@central.ntua.gr
}

Commission V, WG V/2

KEY WORDS: Serious Games, 3D textured Models, Ancient Agora

\begin{abstract}
:
Digital technologies have affected significantly many fields of computer graphics such as Games and especially the field of the Serious Games. These games are usually used for educational proposes in many fields such as Health Care, Military applications, Education, Government etc. Especially Digital Cultural Heritage is a scientific area that Serious Games are applied and lately many applications appear in the related literature. Realistic 3D textured models which have been produced using different photogrammetric methods could be a useful tool for the creation of Serious Game applications in order to make the final result more realistic and close to the reality. The basic goal of this paper is how 3D textured models which are produced by photogrammetric methods can be useful for developing a more realistic environment of a Serious Game. The application of this project aims at the creation of an educational game for the Ancient Agora of Athens. The 3D models used vary not only as far as their production methods (i.e. Time of Flight laser scanner, Structure from Motion, Virtual historical reconstruction etc.) is concerned, but also as far as their era as some of them illustrated according to their existing situation and some others according to how these monuments looked like in the past. The Unity $3 \mathrm{D}^{\circledR}$ game developing environment was used for creating this application, in which all these models were inserted in the same file format. For the application two diachronic virtual tours of the Athenian Agora were produced. The first one illustrates the Agora as it is today and the second one at the $2^{\text {nd }}$ century A.D. Finally the future perspective for the evolution of this game is presented which includes the addition of some questions that the user will be able to answer. Finally an evaluation is scheduled to be performed at the end of the project.
\end{abstract}

\section{INTRODUCTION}

The evolution of new technologies in computer graphics during the recent years has helped significantly the gaming industry and especially the field of Serious Games. This kind of games is spreading rapidly in the field of academic research and is used not only for entertainment but also for educational purposes (Michael et al. 2005; Susi et al 2007). There are many definitions about Serious Games in the literature, however a more formal definition according to Zyda (2005) is: "Serious game: a mental contest, played with a computer in accordance with specific rules, that uses entertainment to further government or corporate training, education, health, public policy and strategic communication objectives". Serious games are applied in many scientific fields which are: Military, Government, Education, Corporate, Healthcare, and Cultural Heritage.

Serious Games for Cultural Heritage applications can significantly help people who are not oriented or specialized in this field such as tourists, school children, college students, museum visitors and others to gain experience and expand their knowledge through these games. This kind of games can be interactive through the use of virtual tour facilities, through posing questions about heritage objects and the monuments and many other similar operations. 3D textured models that have been developed from different methods (Laser scanning, Structure from Motion, Procedural modeling etc.) can be a useful tool for developing Serious Games applications because the player will be able to interact with these models by visiting and answering some question about them.
This study focusses on how 3D textured detailed and realistic models can be used for creating a Serious Game and finally an application of virtual diachronic tours of the Ancient Agora of Athens is attempted. The rest of the paper is organized as follows: Section 2 is a short review of related previous work about Serious Games in the field of Cultural Heritage. Section 3 presents the methodology which is implemented, a description of the available data used for the application development, the Game engine that was used, and the integration of the data and how these virtual tours were developed for the game. Finally in Section 5 the future outlook of this project and some concluding remarks are attempted.

\section{SERIOUS GAMES IN CULTURAL HERITAGE}

So far the implementation of Serious Games in Cultural Heritage has been explored in several projects and many initiatives have already been realized. Anderson et al. (2010) have divided the domain in three areas: prototypes and demonstrations which include games that use visualization and virtual reconstruction in order to train and educate their users. Virtual Museums is another category which uses game technologies in order to provide a means for the presentation of digital cultural heritage sites that entertain and educate visitors. The third category is commercial historical games, which were primarily created for entertainment, but their historical accuracy allows them to be used in educational settings as well. A second categorization of Serious Games according to Mortara et al. (2014) divides the games in many genres which are: Strategy 
Games, Simulation games, Trivia games, Puzzle games and Adventure games.

Many applications have been developed in this field and a lot of them are presented below. The Roma Nova (Roma Reborn) Project, which aims at producing a high resolution version of Rome at 320 A.D. (Frischer 2008), the Ancient Pompeii (Maim et al. 2007) whose goal is to simulate a crowd of Virtual Romans exhibiting realistic behaviours in a district of Pompeii, which has been reconstructed with the help of procedural modeling methods (Muller et al. 2005). The Parthenon project is a short computer animation which visually reunites the Parthenon and its sculptural decorations (Debevec 2005). Virtual reality reconstruction of an Italian city in the Middle Ages is another interesting application of Serious Games (De Paolis et al. 2011). Virtual Egyptian Temple (Jacobson and Holden 2005; Troche and Jacobson 2010) depicts a hypothetical temple which has no real world equivalent. A virtual heritage game which is based on an ancient Egyptian temple in which students can learn from a virtual priest who also challenges students to demonstrate knowledge is the Gate of Horus. The students' reward is the entry into successively deeper and more mysterious parts of the temple (Jacobson et al 2005). The Ancient Olympic Games is the subject of a number of gaming applications associated with Olympic Games in Ancient Greece (Gaitatzes et al. 2004) and was developed by the Foundation of the Hellenic World. Priory Undercrofts game aims to solve a treasure hunt scenario by collecting medieval objects that used to be located in and around of the object which are the remains of the Coventry's original Benedictine monastery, demolished by Henry VIII (Doulamis et al. 2012). Another game is the Battle of Thermopylae in which storytelling techniques and principles of modern videogames are utilized to disseminate historical knowledge about the battle and the associated legends (Christopoulos et al. 2011). THIATRO (Froschauer et al. 2012; Froschauer et al.2013) is an online learning game that immerses the player into an exhibition and, as a side-effect, knowledge of art history concepts are communicated to the player. The Via Appia application is an indirect augmented reality system in which $1 \mathrm{~km}$ of the Via Appia Antica was reconstructed in three time periods and user can explore the notion of narrative movement and travel across space and time in a cultural heritage context, which includes a quiz game with questions related to the information provided in the virtual environments (Liestol 2014). Another game is the "Your Stone to the Building" (Leclet-Groux et al. 2013) in which players teenagers of the age of 11-13 are able to construct the south portal of of the Gothic cathedral of Amiens in France. ICURA is an application in which the user has the opportunity to learn more about Japanese culture and etiquette through gaming (Froschauer et al. 2010). MuseUs is a Serious Game to be used in museums and is running as a smartphone application. In this game the user is invited to create his own exposition and is guided by the application in doing so when he visits a museum (Coenen et al. 2013). MyMuseum is a resource management game that allows large number of players to experience and learn about museum objects by creating their own virtual gallery space with the social networking platform Facebook (Goins 2010). The PLAYHIST experiment is an attempt of developing a Serious Game that will allow players to act and interact posing as a historical character in a $3 \mathrm{D}$ environment recreating one of the Historical moments depicted in the Foundation of Hellenic World (FHW) and he will achieve a better knowledge about history (Perez-Valle et al. 2014). Another Serious Game application is the TouchBIM which includes a touch screen kiosk designed for showing digital heritage contents intuitively and its main goal is to archive and educate the Korean architectural heritage and their construction techniques (Lee et al. 2014). Lercari et al. (2013) developed the Fort Ross Virtual Warehouse Serious Game whose goal is to explore novel ways for archiving, disseminating and teaching cultural and historical information.

Finally, there are many commercial games in which players can learn history. The most known include History Line 1914-1918, Great Battles of Rome and Total War (Belloti et al. 2012).

\section{METHODOLOGY}

The application was developed within Unity 3D Personal ${ }^{\circledR}$ game engine environment (unity3d.com) which is freely available for game development. The Serious Game application which is developed includes two virtual tours of Ancient Agora in Athens in two different time periods. The first one depicts the Agora as it is today and the second presents it as it was in the $2^{\text {nd }}$ century A.D. The target group of this application is people of at least 12 years of age. The basic steps for the development of this Serious Game are presented in Figure 1.

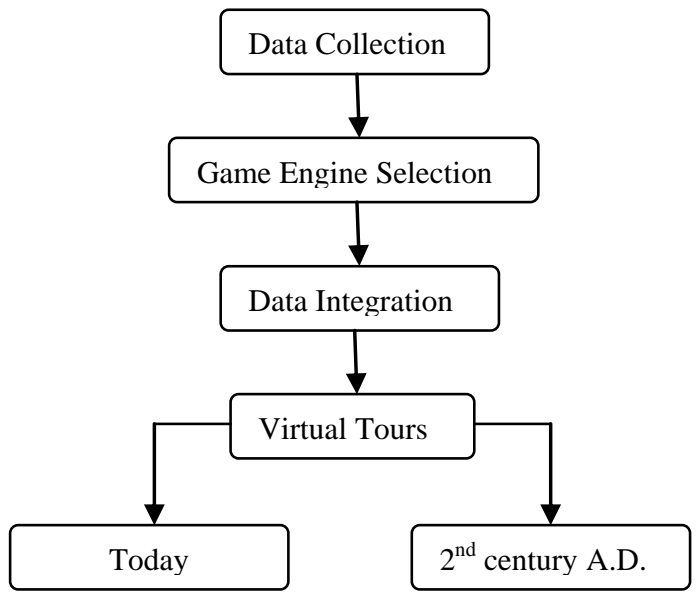

Figure 1: Workflow of the methodology

\subsection{Data available}

For the game development different kind of photogrammetric data were used. Firstly, for the terrain creation, on which the 3D models of the monuments were placed, a raster DSM image and the corresponding orthoimage for the terrain with a GSD of 50 $\mathrm{cm}$ were available for the creation of the $3 \mathrm{D}$ textured terrain (Fig. 2).
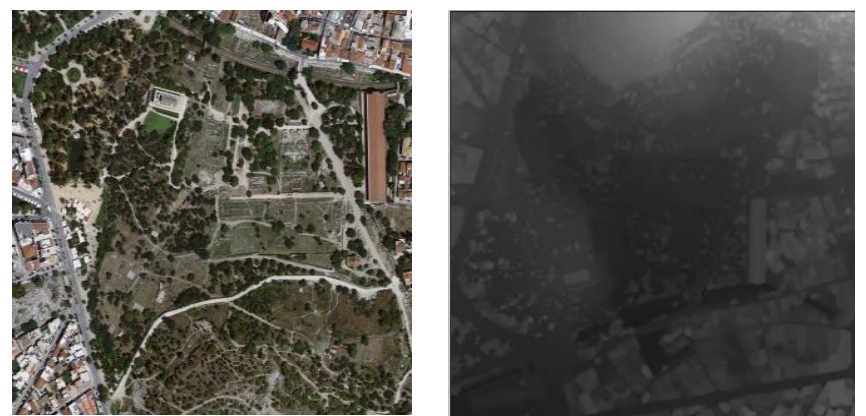

Figure 2: Orthoimage of Ancient Agora (left) and its raster DSM (right) 
Different kinds of 3D textured models were used for the game development. These models vary not only as far as their source in concerned, but also as far as their epoch, because some of them illustrate the existing situation and some others have been historically reconstructed. In Table 1 a categorization of the methods which were used for the creation of the 3D models is presented.

\begin{tabular}{|c|c|}
\hline Category & Name \\
\hline 1 & ToF laser scanner \& overlapping images \\
\hline 2 & ToF Laser scanner with colour information \\
\hline 3 & 3D Historical reconstruction \\
\hline 4 & Structure from Motion (SfM) \\
\hline 5 & 3D Warehouse library \\
\hline
\end{tabular}

Table 1: Categorization of the 3D models

The first category includes the 3D models of the Giant of the Odeion of Agrippa (Fig. 3) created for a Diploma Thesis at the Lab of Photogrammetry of NTUA (Kitsakis 2011) and the southwest side of the Middle Stoa foundations (Fig. 4) which was the result of a postgraduate student work (Karageorgou et al. 2010).

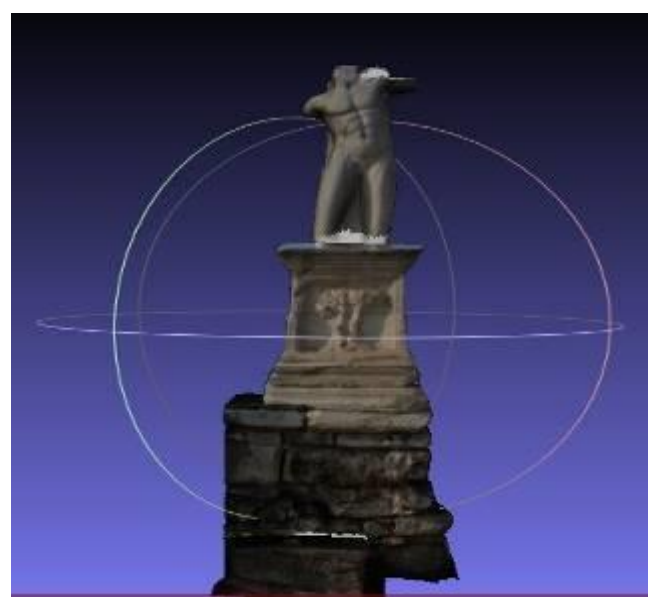

Figure 3: Giant statue of Odeion of Agrippa

A time of flight (ToF) laser scanner, Scanstation 2 of Leica, was used in order to create the 3D models of the monuments without texture. For the texturing phase high resolution digital overlapping images were taken and then oriented and covered the scan models so as to create the final 3D texture models.

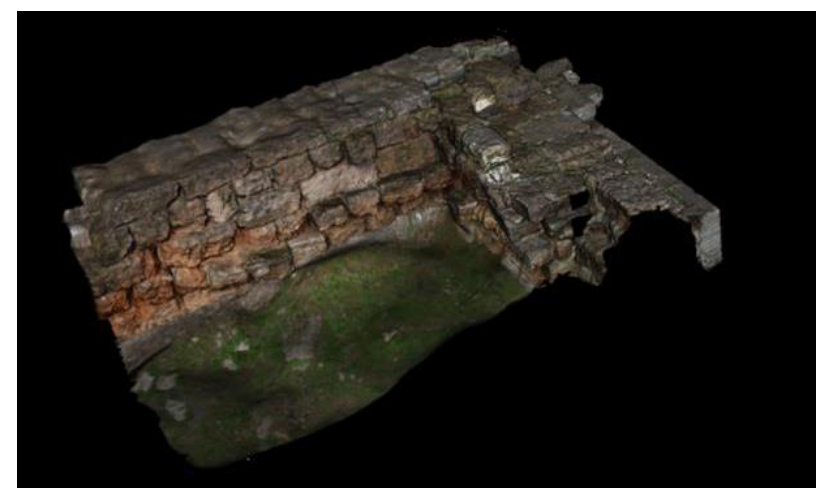

Figure 4: Middle Stoa foundations
The Temple of Hephaestus (Fig. 5) belongs to the second category and its $3 \mathrm{D}$ model was created with a ToF laser scanner that assigns colour information of the points. The texturing phase of the building was carried out in Geomagic Studio ${ }^{\circledR}$ software in which a texture map of each part of the monument was produced in order to texture the final 3D model.

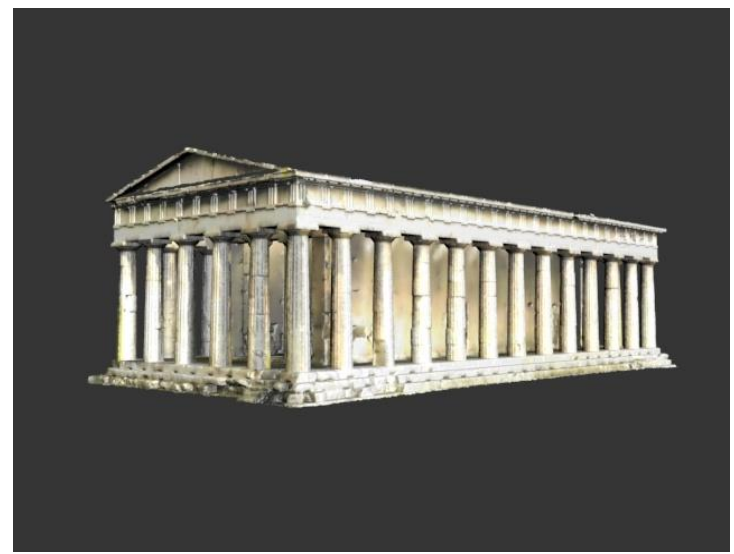

Figure 5: Temple of Hephaestus

The third category includes the southwest side of the Middle Stoa (Fig. 6) whose 3D model was historically reconstructed (Kontogianni et al. 2013). The reconstruction was carried out according to different available data including: old drawings, images, existing literature and experts' assumptions. Especially detail artifacts such as the sima were created with image based Structure from Motion (SfM) techniques and according to Table 1 they belong to the fourth category. All the available data which were used are evaluated according for their verosimility in terms of accuracy and likelihood.

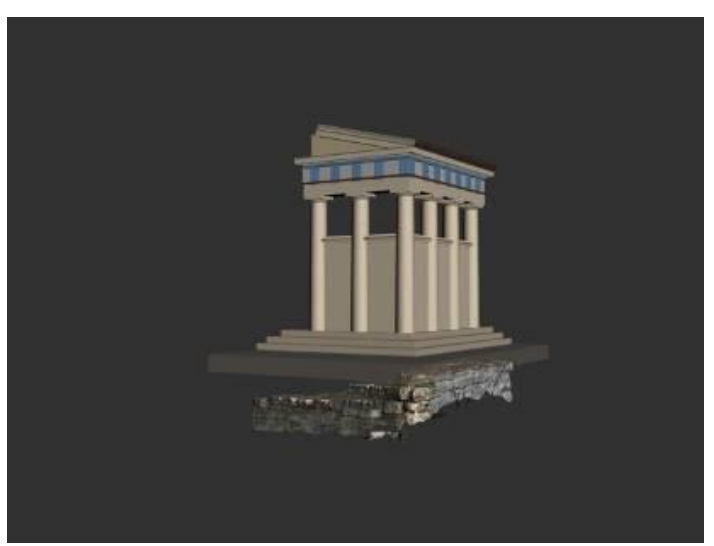

Figure 6: Middle Stoa

In the fourth category belong the models which were created with image based Structure from Motion (SfM) methods. In this category belong the artifacts of the Middle Stoa as it is mentioned above and the 3D model of the Holy Apostles church. For the 3D model of the Holy Apostles church digital images with large overlap were taken from each side of the building except from the north in order to create the 3D model of each side of the church. Agisoft Photoscan ${ }^{\circledR}$ software was used for the creation of the 3D models. These models were then aligned in Geomagic Studio ${ }^{\circledR}$ software with the use of common characteristic points such as windows' corners, doors' corners etc. so as to create the final 3D model of the church (Fig. 7). Because the church has symmetric shape the 3D model of the 
north side is the same as south and it was taken from this and registered to the final model.

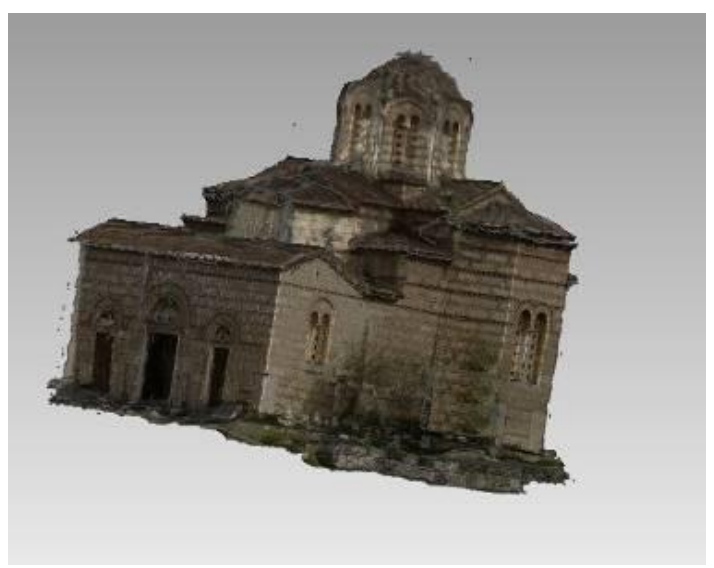

Figure 7: Holy Apostles Church

For the 3D models of the artifacts digital images were taken too but for the procedure the 123D Catch ${ }^{\circledR}$ service by Autodesk was used. These models were inserted into to 3D Studio Max ${ }^{\circledR}$ software and combined to one for the sima's creation (Fig. 8).

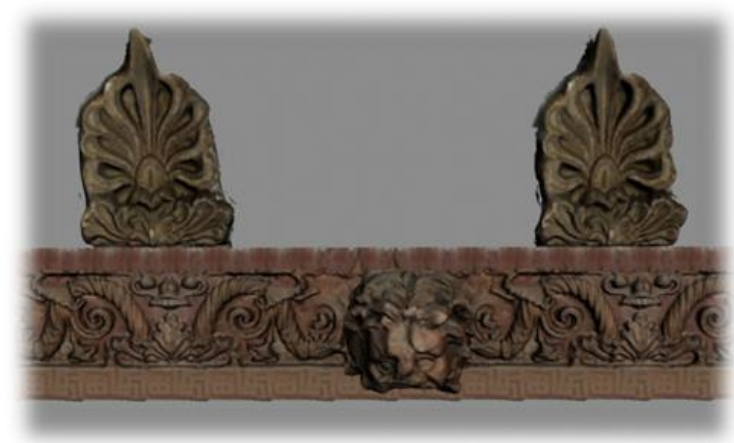

Figure 8: Part of the Sima of the Middle Stoa

In the fifth category belong the models which were taken from the 3D Warehouse library (https://3dwarehouse.sketchup.com/). These models have been developed using the Sketchup ${ }^{\circledR}$ software with which the user can create a 3D model of an object according to its floor plan and then it is textured with images that the user has taken even with his own camera or taken from the Internet. When the 3D model is ready the user can upload it to the Internet in order for other users to see it and even use it. The 3D model of the Stoa of Attalos (Fig. 9) was taken from this website.

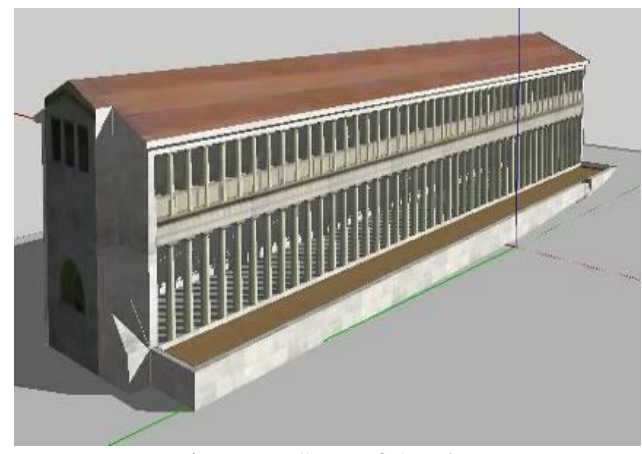

Figure 9: Stoa of Attalos
Finally from the 3D warehouse library additional 3D models of other monuments (Fig. 10) were taken in order to complete the final result. These monuments are: The East Building, the South Stoa II, the Temple of Ares, the Vouleftirion, the Metroon, the Aiakeion, the Tholos and the Fountain House.

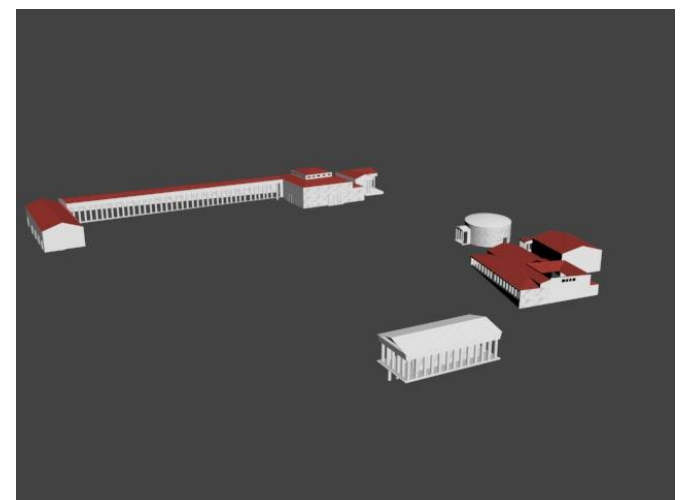

Figure 10: 3D models from 3D Warehouse library

\subsection{Game Engine environment}

Unity $3 \mathrm{D}^{\circledR}$ is a flexible and powerful development platform for creating multiplatform $2 \mathrm{D}$ and $3 \mathrm{D}$ games and interactive experiences. It's a complete ecosystem for anyone who aims to build an application on creating high-end content and connecting to their most loyal and enthusiastic players and customers. It is ideal for building up environments for PC, consoles, mobile devices and websites (https://unity3d.com/). There are two versions of Unity $3 \mathrm{D}^{\circledR}$; the first one called Unity Pro $^{\circledR}$ and is available for a fee and the second one is called Unity Personal ${ }^{\circledR}$ and is free. For the Serious Game application it was decided to use the Personal edition of the software because its free edition has all the tools which are needed for creating of this specific game application.

\subsection{Data Integration}

Firstly an empty terrain is created in Unity ${ }^{\circledR}$, which must have the same dimensions as the DSM image. Then the DSM image of the area is used for the terrain creation. This image was of 32-bit format which is not manageable in the software. For this reason Photoshop ${ }^{\circledR}$ software was used in order to convert the 32-bit image to a raw 16-bit format and to adjust the image dimensions in order for the final DSM image to have the same dimensions as the empty terrain. Then the DSM image was inserted in Unity and applied to the empty terrain. Because of the abrupt variations due to the trees and some present buildings, the terrain was smoothed using the tools available in Unity $^{\circledR}$. Then the terrain was textured using the corresponding orthoimage (Fig. 11).
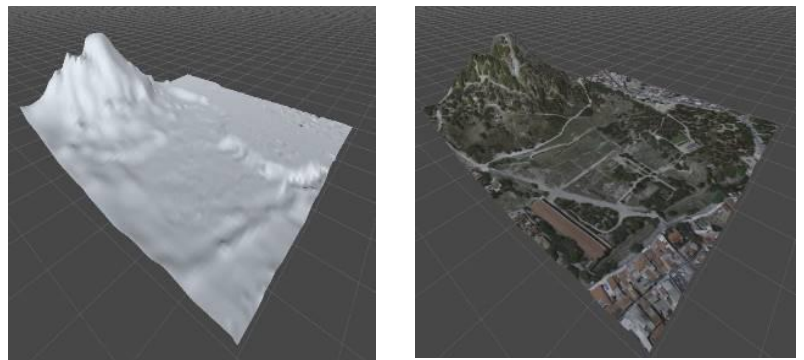

Figure 11: Untextured terrain (left) and textured terrain (right) 
All available 3D models are in different file formats (obj, max, wrp, wrl, dae) because of their different methods of production. For this reason all models were converted to fbx format which can be managed by Unity ${ }^{\circledR}$. Moreover, for the insertion of the models of the Temple of Hephaestus and of the Middle Stoa foundations, the information was decimated to $70 \%$ to make them easier for Unity ${ }^{\circledR}$. Subsequently the 3D models were inserted into the software. After the insertion some problems were detected in the texture of some models. First of all in some models created with SfM or laser scanner the texture was not applied. In this case the texture was applied manually by inserting the textures again. A second problem was that in the 3D models of Holy Apostles church and Temple of Hephaestus the texture was too dark (Fig. 12).
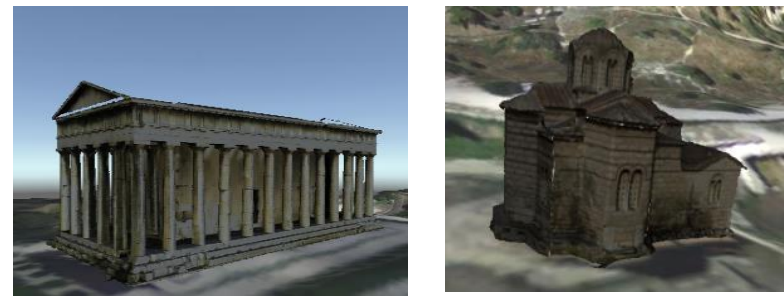

Figure 12: Temple of Hephaestus (left) and Holy Apostles church (right) with the wrong texture

The problem was caused because Unity except the texture applies colour information in the textured models. This colour was grey and it was the reason that the models were too dark. This problem was solved by changing this colour from grey to white in the colour pallet in Unity ${ }^{\circledR}$ and finally the models had the right colour in the texture.
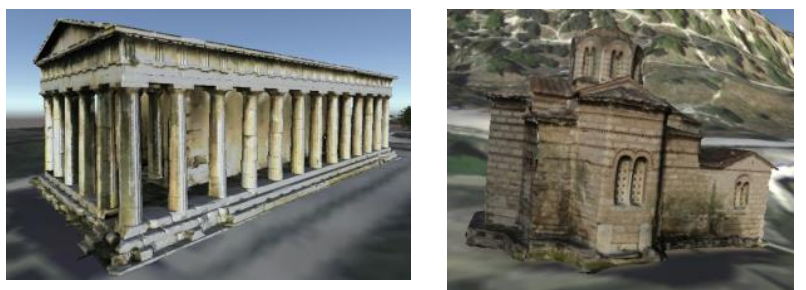

Figure 13: Temple of Hephaestus (left) and Holy Apostles church (right) with the right texture

Furthermore the 3D models from the 3D warehouse library had some mistakes such as the colour of the models and the colonnade in the Temple of Ares in which columns penetrated the ground. These mistakes were corrected before or after inserting the 3D models into Unity 3D. Finally all the models were in place (Fig. 14) and the next step is the development of the game application. Furthermore, some trees were added for more realistic results. They were taken from the 3D warehouse library.

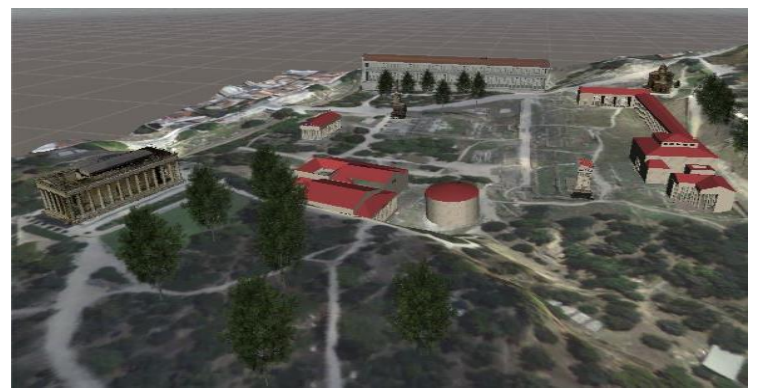

Figure 14: An overview of the game environment

\subsection{Diachronic Virtual Tours}

As mentioned above, an application for virtual tours for the Ancient Agora was created for the user to be able to virtually move at will to any direction. Two versions of the virtual tours were created; the first one presented the Agora as it is today and the second one as it was in the $2^{\text {nd }}$ century A.D. The lighting of the game environment was performed with the lighting tool in Unity software. A main light and a fill light were chosen for the result to be more realistic and close to the reality. Additionally a skybox was added in order to complete this realistic result. The virtual tours for the Ancient Agora were performed with the use of First Person Controller tool available in Unity. This tool included a camera attached in a simple 3D mesh and the player can move by simply using the arrow keys of the keyboard and the mouse. Finally, the name of each monument was flaged beside or above each model (Fig.15) in order for the player to recognize which monument he virtually visits.

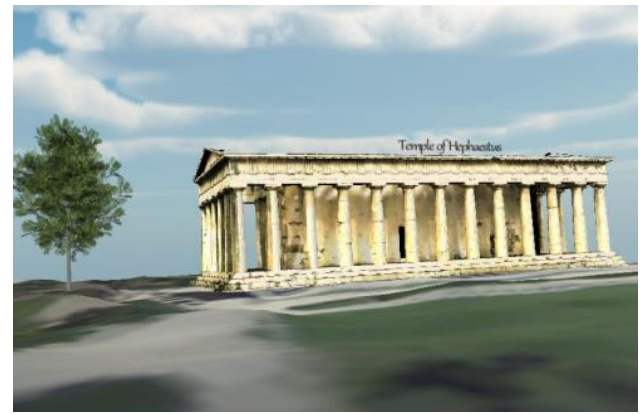

Figure 15: A screenshot of the virtual tour

Furthermore a game should have a selection menu in order to help the player select what he/she wants to do. For the case of the application of the virtual tour for the Ancient Agora of Athens this selection menu (Fig. 16) has the choice of which tour the user wants to follow. As it is mentioned above these choices are a virtual tour of today and a virtual tour of the area at a specific time in the past. Additionally a help tool was added in order for the player to read some instructions about the virtual tour.

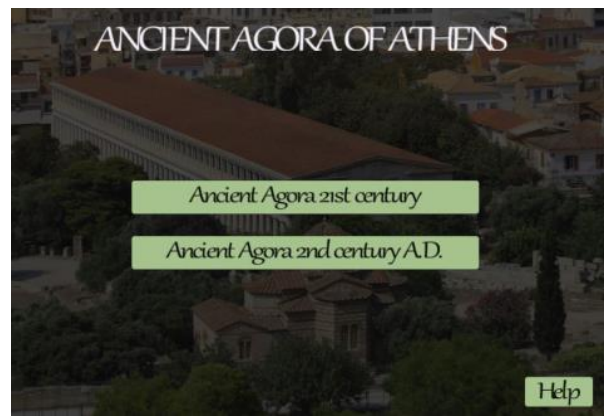

Figure 16: Main Menu of the application

A simple script was created in C\# programming language for the use of buttons. The script gives the opportunity to the user to select which virtual tour he wants to chose and to continue with his selection when he presses the appropriate button. Furthermore in Game mode a GUI button was added (Fig. 17) in order for the user o be able to return to the main menu or to continue with another virtual tour. 


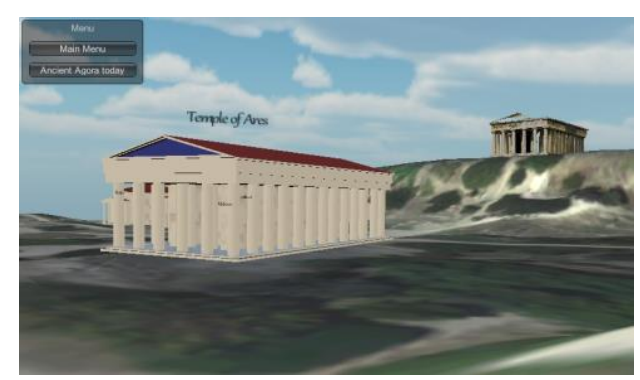

Figure 17: An overview of the game with the GUI window

\section{CONCLUDING REMARKS AND FUTURE OUTLOOK}

The game is still under development so the enrichment of the application with more options is necessary and underway. The first one is the creation of a quiz game in which the user will be asked to answer some questions about each monument he visits. These questions will be about the history, the architecture of each monument etc. In case of a correct response the user will be able to continue. In case of a wrong answer, the game will educate the user giving him/her the correct response and then allow him/her to continue. The establishment of a point system will be a further option which means that the user wins points for each correct answer and will be sent to the starting point after e.g. two wrong answers.

The evaluation of the game is scheduled to be performed at the end of the project. This evaluation may include the playing of the game by a group of people who are experts in cultural heritage and also people who know the basics about this field. They will be asked to play the game and they will fill an online questionnaire for the evaluation of the game. More models of monuments or the replacement of those which were taken from the 3D Warehouse for more realistic results are planned for the future.

The 3D models that were developed from the ToF laser scanner were a little difficult to manage inside Unity mainly because of their size. Because of this problem it was decided to reduce the size of these models to the $70 \%$ of the information as already mentioned. On the other hand it is very useful to use realistic 3D models for creating Serious Games applications, because the player can see how the monument looked like in the case that the monument does not exist and how some monuments are today in cases that the user is not able to visit them for various reasons.

\section{REFERENCES}

Anderson, E. F., McLoughlin, L., Liarokapis, F., Peters, C., Petridis, P., De Freitas, S. , 2010. Developing serious games for cultural heritage: a state-of-the-art review. Virtual reality, 14(4), pp. 255-275.

Bellotti, F., Berta, R., De Gloria, A., Dursi, A., Fiore, V., 2012. A serious game model for cultural heritage. Journal on Computing and Cultural Heritage (JOCCH), 5(4), p. 17.

Christopoulos, D., Mavridis, P., Andreadis, A. \& Karigiannis, J. N., 2011. Using Virtual Environments to Tell the Story:" The Battle of Thermopylae". $3^{\text {rd }}$ Internationa Conference on Games and Virtual Worlds (VS-GAMES 2011),Athens Greece, 4-6 May, pp. 84-91.
Coenen, T., Mostmans, L. \& Naessens, K., 2013. MuseUs: Case study of a pervasive cultural heritage serious game. Journal on Computing and Cultural Heritage (JOCCH), 6(2), p. 8.

De Paolis, L., Aloisio Maria G., Celentano M.G., Oliva L., Vecchio P. 2011. Otranto in the Middle Ages. a serious game for the edutainment. International Journal of Information and Education Technology, Vol.1 No 1 pp. 47-57.

Debevec, P., 2005. Making" The Parthenon. $6^{\text {th }}$ International Symposium on Virtual Reality, Archaeology and Intelligent Cultural Heritage (VAST 2005), Kent UK.

Doulamis, A., Liarokapis, F., Petridis, P. \& Miaoulis, G., 2012. Serious games for cultural applications. In: Intelligent Computer Graphics 2011. Springer, pp. 97-115.

Frischer, B., 2008. The Rome Reborn Project. How Technology is helping us to study history. OpEd, November, Volume 10.

Froschauer, J., Arends, M., Goldfarb, D. \& Merkl, D., 2012. A serious heritage game for art history: Design and evaluation of ThIATRO. $18^{\text {th }}$ International Conference on Virtual Systems and Multimedia (VSMM 2012), Milan Italy, 2-5 September, pp. 283-290.

Froschauer, J., Merkl, D., Arends, M. \& Goldfarb, D., 2013. Art history concepts at play with ThIATRO. Journal on Computing and Cultural Heritage (JOCCH), 6(2), p. 7.

Froschauer, J. Berger H., Merkl D. 2010. Design and evaluation of a Serious Game for immersive cultural training. $16^{\text {th }}$ International Conference on Virtual Systems and Multimedia (VSMM 2010), Seoul Korea, 20-23 October, pp. 253-260.

Gaitatzes, A., Christopoulos, D. \& Papaioannou, G., 2004. The ancient olympic games: being part of the experience. $5^{\text {th }}$ International Symposium on Virtual Reality, Archaeology and Intelligent Cultural Heritage (VAST 2004), Oudenaarde, Belgium, December 7-10, pp. 19-28.

Goins, E., 2010. Art history in the 21st century: The integration of museum collections and social networking games. International Conference on Education and New Learning Technologies, Barcelona Spain, 5-7 July, pp. 5516-5525.

Jacobson, J. \& Holden, L., 2005. The virtual egyptian temple., pp. 4531-4536. World Conference on Educational Media and Technology, Montreal, Canada, 25 June.

Jacobson, J., Handron K., Holden L.,2009, Narrative and Content Combine in a Learning Game for Virtual Heritage. Distance Education 9.2 (2009): 7-26.

Karageorgou, M., Barakou, A., Briana, D., Siora E., 2010, 3D model of the south-western corner of the Middle Stoa in the Athens Agora, Large scale surveys student project, Msc in Geoinformatics , School of Rural \&Surveying Engineering, NTUA (in Greek).

Kitsakis, D., 2011. Evaluation of photogrammetric methods of $3 D$ data acquisition. Diploma Thesis, National Technical University of Athens. 
Kontogianni, G., Georgopoulos, A., Saraga, N., Alexandraki, E., Tsogka, K., 2013. 3D VIRTUAL RECONSTRUCTION OF THE MIDDLE STOA IN THE ATHENS ANCIENT AGORA, . ISPRS - International Archives of the Photogrammetry, Remote Sensing and Spatial Information Sciences, Vols. XL5/W1, pp. 125-131

Leclet-Groux, D., Caron, G., Mouaddib, E. \& Anghour, A., 2013. A Serious Game for 3D cultural heritage. Digital Heritage International Congress, Digital Heritage 2013, Marseille France, 28 October-2 November , pp. 409-412.

Lee J., Kang K. K., Kim J.W., Lee J., Goo B., 2014. TouchBim: A Touch Screen Kiosk for Education of Korean Traditional Wooden Building. In: Proceedings of EuroMed 2014 International Conference on Cultural Heritage, 3-8 November, Limassol, Cyprus.

Lercari, N., Mortara, M. \& Forte, M., 2014. Unveiling California History Through Serious Games: Fort Ross Virtual Warehouse. In: Games and Learning Alliance. Springer, pp. 236-251.

Liestol, G., 2014. Along the Appian Way. Storytelling and Memory across Time and Space in Mobile Augmented Reality. In: Digital Heritage. Progress in Cultural Heritage: Documentation, Preservation, and Protection. Springer, pp. 248-257.

Maim, J., Haegler, S., Yersin, B., Muller, P., Thalmann, D., Van Gool L. 2007. Populating ancient pompeii with crowds of virtual romans. In Proceedings $8^{\text {th }}$ International Symposium on Virtual Reality, Archaeology and Cultural Heritage (VAST 2007), Brighton UK, 26-30 November.

Mortara, M. et al., 2014. Learning cultural heritage by serious games. Journal of Cultural Heritage, 15(3), pp. 318-325.

Michael, D. R. \& Chen, S. L., 2005. Serious games: Games that educate, train, and inform. Muska \& Lipman/Premier-Trade, ISBN 1592006221.

Muller, P., Verrenooghe T., Ulmer A., Van Gool L., 2005. Automatic reconstruction of Roman housing architecture. Recording Modeling and Visualization of Cultural Heritage.Taylor \& Francis Group, London, ISBN 041539208

Perez-Valle, A., Aguirrezabal, P. \& Sillaurren, S., 2014. Playhist: Play and Learn History. Learning with a Historical Game vs An Interactive Film. In: Digital Heritage. Progress in Cultural Heritage: Documentation, Preservation, and Protection. Springer, pp. 546-554

Susi, T., Johannesson, M. \& Backlund, P., 2007. Serious games: An overview.

Troche, J. \& Jacobson, J., 2010. An exemplar of Ptolemaic egyptian temples. In Proceedings 38th Conference on Computer Applications and Guantitative Methods in Archaeology (CAA 2010), Granada, Spain, April .

Zyda M., 2005. From visual simulation to virtual reality to games, Computer, 38(9), 25-32.

unity3d.com, Unity 3D software (Last visited 26/6/2015) https://3dwarehouse.sketchup.com/, 3D warehouse library (Last visited 20/6/2015) 